\title{
Response of Bentgrass Cultivars to Microdochium nivale Isolates Collected from Golf Courses
}

\author{
Taehyun Chang ${ }^{1 *}$,Seogwon Chang ${ }^{2}$ and Geunhwa Jung ${ }^{3 *}$ \\ ${ }^{1}$ Plant Resources and Environment Major, Kyungpook National University, Sangju 742-711, Korea \\ ${ }^{2}$ Department of Golf Course Management, Korea Golf University, Hoengseong 225-811, Korea \\ ${ }^{3}$ Department of Plant, Soil \& Insect Sciences, University of Massachusetts, Amherst, MA 01003,USA \\ (Received on December 16, 2010; Revised on March 28, 2011; Accepted on July 21, 2011)
}

Pink snow mold, caused by Microdochium nivale, is a major disease on cool season turfgrasses in golf courses in northern Unites States. The relative susceptibility of 17 commercial cultivars of three bentgrass species (creeping, colonial and velvet bentgrass) to Microdochium nivale and the aggressiveness of $M$. nivale eight isolates obtained from infected turfgrasses on golf courses in Wisconsin were evaluated under controlled conditions. For the field trial, susceptibility of 2 year-old 12 commercial bentgrass cultivars was evaluated after inoculating three $M$. nivale isolates in the fields. There were significant differences in disease severities among the three bentgrass species, particularly between tetraploids (creeping and colonial) and diploid (velvet) species, and among cultivars within each species, indicating that there are varying levels of susceptibility in species and cultivars to $M$. nivale. Host resistance by days of cold hardening was confirmed, by detecting the resistance by 30 days of cold hardening treatments. In field trial, susceptibility of 12 bentgrass cultivars was highly correlated to the results obtained from growth chamber experiments. The positive correlation of the susceptibility between growth chamber experiments and field trials demonstrates that the growth chamber method is a useful technique for saving time, space and labor to evaluate efficiently pink snow mold susceptibility of bentgrass cultivars. This study could be applied to evaluating susceptibility of bentgrass to pink snow mold and also predicting a prospective evaluation of bentgrass cultivars to pink snow mold in fields in a breeding program.
Keywords : bentgrass, hardening, host resistant, Microdochium nivale, mycelium suspension

Pink snow mold, caused by Microdochium nivale (syn. = Fusarium nivale), is a major disease of cereals and turfgrasses in the cold to temperate regions of the northern hemisphere (Arsvoll, 1977) This disease develops in turfgrasses in the absence of a permanent snow cover or it may develop at any time of the year during cool, high humidity and wet weather (Latch, 1973; Smith, 1957; Smiley et al., 1992). Disease symptoms appear at the end of the winter, after snow melt. As the winter snow cover melts exposed patches appear bleached and are often covered with abundant, white mycelium, which may mat together the leaf blades. The patches may gradually turn pink as the mycelium matures and sporodochia form.

$M$. nivale has 85 grass hosts, many of which are forage grasses (Couch, 1973). Using as a turfgrass, bentgrass species (Agrostis species) were more susceptible to the fungus than Kentucky bluegrass (Poa pratensis) and ryegrass species (Lolium spp.). Bentgrass is a large genus with over 100 species, and is considered the most important turfgrass in the turfgrass industry (Hitchcock, 1951). The three bentgrass species commonly used for golf course in the United States are creeping (A. stolonifera L.), colonial (A. capillaries L.), velvet (A. canina L.).

Pink snow mold severity can be reduced by several cultural practices such as moisture control and maintenance of turf vigor, and fertility control such as application of late fall nitrogen fertilizer (Dahl, 1934; Madison, 1960; Smith et al., 1989; Tyson, 1936). Currently, pink snow mold management, is highly dependent on chemical fungicide application (Smith et al., 1989). Affordable fungicides such as PCNB are no longer registered for use in the United States due to environmental concerns (Smith et al., 1989). Other fungicides increase disease management costs to golf course managers. Therefore, there is a need for alternative disease management strategies such as host resistance to $M$. nivale

\footnotetext{
*Corresponding authors.

TH Chang

Phone) +82-54-530-1204, FAX) +82-54-530-1209

E-mail: thchang@knu.ac.kr

GH June

Phone) +1-413-545-2243, FAX) +1-413-545-3075

E-mail: jung@psis.umass.edu
} 
in bentgrass cultivars. Resistant cultivars would greatly reduce the costs and environmental impacts of fungicide application. However, little research on current cultivar resistance has been done. A good understanding of both the pathogen and the host biology is required to implement host resistance by selecting resistant cultivars. The breeder needs information regarding different isolates of the pathogen and their virulence variability to understand potential host resistance to the pathogen.

Field evaluation for cultivars resistant to pink snow mold is often inefficient due to several many factors as a environmental, space (Smith et al., 1989). For screening of bentgrass cultivars resistance to $M$. nivale isolates, good methods, has not been developed for in vitro using artificial inoculum with several isolates. A new method for controlled growth chamber experiments is needed. In particular, inoculum production of $M$. nivale isolates has been problematic on laboratory level. For example, Holmes and Channon (1975) introduced macerated mycelium or spore suspensions of $F$. nivale in the soil between perennial ryegrass seeding, and the process failed to incite infection.

The objectives of this study include: evaluation of susceptibility to $M$. nivale isolates among current bentgrass cultivars in field and growth chamber, effect of light during cold hardening on disease development, and effect of cold hardening days on susceptibility of bentgrasses.

\section{Materials and Methods}

\section{Growth chamber inoculation.}

Plant materials and cold hardening: Seventeen bentgrass cultivars ( 9 creeping, 5 colonial and 3 velvet) were used for this study (Table 1). Cultivars of creeping and colonial bentgrass or velvet bentgrass cultivars were sown using $0.08 \mathrm{~g}$ of seeds, $0.05 \mathrm{~g}$ of seeds evenly spread in $2.5^{\prime \prime} \times 2.5^{\prime \prime}$ pots with potting soil (Metro Mix 366-P, Scott's company), respectively. The plants were grown in the greenhouse at 18 to $28^{\circ} \mathrm{C}$ with light and dark cycle of 16 and 8 hours, respectively. The plants were mowed with scissors at 0.5 $\mathrm{cm}$ to $0.7 \mathrm{~cm}$ ranges until 80 days old, at which time they were adult plants. Water soluble fertilizer (21-5-20: SunGrow company, Texas) at $2 \mathrm{~g}$ per $1 \mathrm{~L}$ was applied weekly after was the beginning of mowing at 21 days. These plants were used for all in vitro experiments (Fig. 1C).

For cold hardening, bentgrass cultivars grown for 80 days in a greenhouse, were transferred to growth chambers and, hardened at $5^{\circ} \mathrm{C} \pm 1$ to be controlled with light and no light for 15 days up to 45 days according to purposes of experiments before inoculated with M. nivale isolates (Fig. 1C). No light treated bentgrass in the growth chamber was kept in dark during the period of cold hardening. For lights treatment, fluorescent light were arranged $100 \mathrm{~cm}$ directly above plants in the growth chamber. Illumination was maintained with light/dark cycles of 8 and $16 \mathrm{~h}$ through the hardening. Plants were supplied with distilled water for hardening.

Fungal isolates: Isolates of eight $M$. nivale strains used in this study were selected from 160 isolates, which were previously collected from more than one hundred golf courses

Table 1. Bentgrass cultivars and sources used in this study

\begin{tabular}{llll}
\hline \hline Bentgrass species & Cultivars & Lot number & Sources \\
\hline Creeping & Penncross* & L36-0-109 & TURF-SEED, INC., Hubbard, OR \\
& PennA4* & M52-9-A4-1 & TURF-SEED, INC., Hubbard, OR \\
& PennG2* & M33-0-57 & TURF-SEED, INC., Hubbard, OR \\
& Penneagle II* & C8-1-OPN-BS & TURF-SEED, INC., Hubbard, OR \\
& Pennlinks II* & C8-1-OVN-BS & TURF-SEED, INC., Hubbard, OR \\
& PST-9BNC* & C8-1-9BNC-BS & TURF-SEED, INC., Hubbard, OR \\
& Providence & PRB51 & Old Seed Solutions: P.O. Box 7790 \\
& L93 & L93 22 & Old Seed Solutions: P.O. Box 7790 \\
& Pennlinks* & PLB 12 & Old Seed Solutions: P.O. Box 7790 \\
& SR7100* & SR71 11 & Old Seed Solutions; P.O. Box 7790 \\
& Tiger & LA20-0-121472 & CEBECO INT. SEEDS, INC., Halsay OR \\
& Alister* & M65-1-9F7-F & TURF-SEED, INC., Hubbard, OR \\
& Glory* & M65-1-9HG-F & TURF-SEED, INC., Hubbard, OR \\
& Bardot* & M65-1-9HB-F & TURF-SEED, INC., Hubbard, OR \\
& Greenwich* & M146-1-81 & TURF-SEED, INC., Hubbard, OR \\
& Bavarica & M146-1-82 & TURF Merchants, INC., Tangent, OR \\
& Vesper & L79-0-VB49 & TURF Merchants, INC., Tangent, OR
\end{tabular}

*Cultivars were used in the field trial 


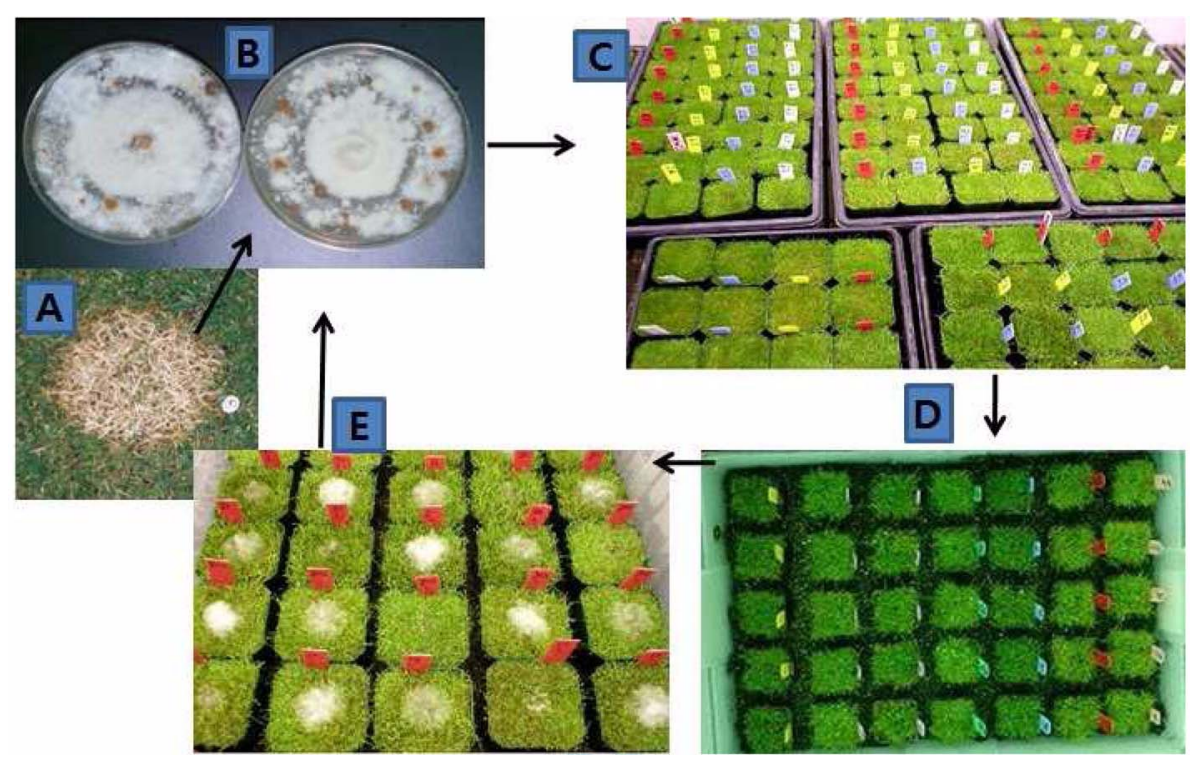

Fig. 1. Outline of the cooling system and inoculation procedure. (A) Symptom in the field. (B) Preparation of M. nivale isolates for inoculation. (C) Bentgrass cultivars were hardened at $5^{\circ} \mathrm{C} \pm 1$ to be controlled with or without light for 15 days. (D) Inoculation with eight isolates of $M$. nivale at $10^{\circ} \mathrm{C}$ in the dark after cold hardening at $5^{\circ} \mathrm{C}$ for 15 days. (E) Disease development.

in Wisconsin during 2001. The isolates were chosen from different regions based on their genetic diversity. 160 isolates were analyzed to detect their varieties using specific primers with a theoretical melting temperature around $62^{\circ} \mathrm{C}$. Two primers pairs were generated. The fiest primer pair as the forward and the reverse, Y 13MF/Y13 MR (CTTGAGGCGGAAGATCGC/ATCCCTTTTCCGGGGTTG) for the detection of $M$. nivale var majus and the second primer pair as the forward and the reverse, $\mathrm{Y} 13 \mathrm{NF} /$ Y13NR (ACCAGCCGATTTGTGGTTATG/GGTCACGAGGCAGAGTTCG) for the detection of $M$. nivale var. nivale. The specificity of the primer pairs was tested against a range of $M$. nivale isolates associated with pink snow mold. Pathogenicity of isolates had been tested on two cultivars of bentgrass prior to all the mentioned experiments in this manuscript (data not shown). Isolates were maintained as pure cultures grown on sucrose nutrient agar (SNA) medium (Nagasima and Abe, 1996) at $4^{\circ} \mathrm{C} \pm 1$ and subcultured regularly. The origins of the eight isolates are listed in Table 2. Before use for the inoculation, all isolates were sub-cultured on Difco potato dextrose agar (PDA) at $20^{\circ} \mathrm{C} \pm 1$ for 7 days in the dark.

Inoculums production: Mycelium suspensions were produced by taking twenty culture plugs of $5 \mathrm{~mm}$ in diameter from the colony edge and transferred to $100 \mathrm{ml}$ Difco potato dextrose broth (PDB) and grown at $20^{\circ} \mathrm{C} \pm 1$ for 10 days in the dark. Mycelia were harvested from PDB culture by filtration on cheesecloth. After drying for $15 \mathrm{~min}$ under a clean hood, the weights of fresh mycelia were measured.
The mycelia were homogenized for 30 seconds in a blender with sterile distilled water. These suspensions were adjusted with sterile distilled water to a final concentration of $0.2 \mathrm{~g}$ fresh mycelium weight per $\mathrm{ml}$ for growth chamber inoculations.

Inoculation and incubation methods. Inoculations of bentgrass cultivars seeding were used to develop the localized inoculation directly on the plants as a final concentration of $0.2 \mathrm{~g}$ fresh mycelium weight per $\mathrm{ml}$ per pot using a micropipette for all growth chamber assays. Incubation was used to develop the plastic containers method. The plastic incubation containers were filled by mixing $4 \mathrm{~L}$ of potting soil (Metro Mix 366-P, Scott's company) and $4 \mathrm{~L}$ of distilled water for maintaining high humidity before inoculated plant was placed (Fig. 1D). The inoculated pots were arranged in a randomized complete block design with four replicates in a plastic container $(70 \times$ $40 \times 15 \mathrm{~cm}$, Rubbermaid, Wooster, OH). To keep moisture in the plastic containers for 10 days, was applied by evenly spraying on the plants with distilled water using a hand sprayer until saturation, was covered with containers cover to maintain the high humidity to disease infection and development. Incubation containers were maintained at $10^{\circ} \mathrm{C}$ in the dark for 10 days in growth chamber. Disease infection and colonization were assessed at 7 days and 10 days after inoculation (Fig. 1F).

Determination of amount of inoculum: The creeping bentgrass cultivar 'Penncross', colonial bentgrass cultivar 
'Tiger', and velvet bentgrass cultivar 'Greenwich', were used to determine ideal inoculums concentration for growth chamber experiment. Eighty day old plants were cold hardened in a growth chamber for 15 days. Three $M$. nivale isolates (SE25, SW47 and NW70) were used in the experiment. Mycelium suspension inoculums was prepared at final concentration, of $0.05 \mathrm{~g}, 0.1 \mathrm{~g}, 0.2 \mathrm{~g}$, and $0.4 \mathrm{~g}$ fresh mycelium weight per $\mathrm{mL}$ with sterile distilled water. The inoculation was made by injecting $1 \mathrm{ml}$ of the inoculums suspension directly onto the plants in the center of the pots using a micropipette.

Susceptibility of bentgrass cultivars: Seventeen commercial bentgrass cultivars were evaluated for their susceptibility to $M$. nivale isolates, given in Table 2 . These plants were hardened for 15 days in the dark before inoculated with $M$. nivale isolates. Eight $M$. nivale isolates were used as inoculum. Inoculation and incubation were followed as described above.

Effect of lights and days of cold hardening. To investigate effects of light and no light on disease infection and colonization and of host resistance response by days of cold hardening to $M$. nivale isolates, two creeping bentgrass cultivars (Penncross and pennA4), two colonial bentgrass cultivars (Glory and Tiger) and two velvet bentgrass cultivars (Greenwich and Vesper) were used. These cultivars were hardened at $5^{\circ} \mathrm{C} \pm 1$ to be controlled with light and no light for 15 days to investigate effects of light and to investigate host resistance by days of cold hardening before inoculation for 15 days, 30 days and 45 days. Three isolates (SE 25, SW 47 and NW 70) of $M$. nivale were used. Inoculation and incubation were followed as described above.

\section{Field trial.}

Susceptibility of bentgrass cultivars: The twelve commercial bentgrass cultivars were evaluated for their susceptibility to $M$. nivale isolates (Table 1) at the O. J. Noer Turfgrass Research Center in Verona, Wisconsin during 2004-2005. The experimental design was a completely randomized block design with 4 replications, with a plot size of $90 \mathrm{~cm} \times 120 \mathrm{~cm}$. The sowing rates were those normally recommended by the seed company and were made on October 30,2002. The plots were maintained with fairway height mowing and fertilizer application for 2 years. Three isolates (SE 25, SW 70 and NW 105) of $M$. nivale were used. Wheat grain inoculums were prepared by autoclaving $40 \mathrm{~g}$ of oat seeds with $40 \mathrm{~mL}$ PDB in $250 \mathrm{~mL}$ Pyrex flasks and re-autoclaving them after 24 hours. Ten culture plugs of $5 \mathrm{~mm}$ in diameter were taken from the edge of the actively growing fungal colonies from the PDA plates and transferred to the oat seed medium. They were allowed to grow for three weeks at $20^{\circ} \mathrm{C} \pm 1$ in dark, and daily shook to prevent clumping of the seeds. Before inoculation, the inoculum was dried for 24 hours under a clean hood. Inoculations were performed by placing five infected oat seeds at five locations on each plot on October 20, 2004.

Disease assessment and statistical analysis: Disease severity in growth chamber experiments was assessed by measuring diameter (millimeter) of infection areas using a digital caliper (Mitutoyo Co.) 7 days after inoculation. Incubation period was determined by examining the plant in each pot for disease infection and colonization. Disease rating in field was measured twice on March 20 and 26, 2004 after snow melt. The size of disease infection and colonization on plants were estimated by measuring patches' diameter by a scale ruler.

All statistical analyses were conducted using general linear models procedure (PROC GLM) in SAS (SAS institute Inc., Cary, NC). Replications were treated as a random effect and cultivars within species and isolates as fixed effects. Means were compared with Fisher's protected least significant differences test at $P \leq 0.05$. For all primary and derived parameters, analysis of variance (ANOVA) was used to test the significance of main effects (cultivars within species and isolate) and the first order interaction (cultivar $\times$ isolate). The source of variation for bentgrass species was partitioned into two orthogonal contrasts: creeping bentgrass and colonial (tetraploidy) vs. velvet bentgrass (diploid), and creeping bentgrass vs. colonial (different genomes within tetraploidy). The experiments were repeated twice, and the results of each experiment were analyzed separately.

\section{Results}

Identification of the isolates and determination of the amount of inoculums. Eight isolates used in this study was identified $M$. nivale, and produced spores in a pinkish matrix of mycelium and sporodochia on PDA (Table 2, Fig. 1B). ANOVA detected that there were effects of concentration of inoculums $(P<.0001)$ and isolates $(P<.0001)$ on disease infection and colonization in three bentgrass cultivars (Table 3 ). For this experiments detected that there was a significantly difference $(P<.0001)$ with increased concentration of inoculums to three $M$. nivale isolates.

Susceptibility test for bentgrass cultivars. Based on two growth chamber experiments (Table 4), there were significant differences $(P=0.05)$ of disease infection and colonization of $M$. nivale isolates to 3 bentgrass species. Cultivars 
Table 2. Eight isolates of Microdochium nivale used in this study and their collection sites

\begin{tabular}{lccc}
\hline \hline Isolate & $\begin{array}{c}\text { Identification of } \\
\text { PCR }\end{array}$ & Spore & Collected locations \\
\hline NW 24 & $\begin{array}{l}\text { M. nivale } \\
\text { NW 70 }\end{array}$ & Yes & North West, WI in 2001 \\
NW105* & M. nivale & Yes & Yorth West, WI in 2001 \\
SW1 & M. nivale & Yes & Sorth West, WI in 2001 \\
SW47* & M. nivale & Yes & South West, WI in 2001 \\
NE37 & M. nivale & Yes & North East, WI in 2001 \\
SE33 & M. nivale & Yes & South East, WI in 2001 \\
SE25* & $M$. nivale & Yes & South East, WI in 2001 \\
\hline
\end{tabular}

*Isolates used in the field trail

Table 3. Analysis of variance for determination of amount of inoculums of three bentgrass cultivars inoculated with four different concentrations of three $M$. nivale isolates at $10^{\circ} \mathrm{C}$ in the dark after cold hardening at $5^{\circ} \mathrm{C}$ for 15 days

\begin{tabular}{lccc}
\hline \hline \multirow{2}{*}{ Source } & df & \multicolumn{2}{c}{ Disease infection size $(\mathrm{mm})$} \\
\cline { 3 - 4 } & & F value & $P$ value \\
\hline Replication & 3 & 2.5445 & 0.0599 \\
Cultivars & 2 & 39.8923 & $<.0001$ \\
Concentration [isolate] & 9 & 75.0652 & $<.0001$ \\
Isolate & 2 & 22.2647 & $<.0001$ \\
Concentration [isolate] & 18 & 0.6400 & 0.8605 \\
$\times$ Cultivars & & & \\
Error & 109 & & \\
\hline
\end{tabular}

within species and Isolates had a significant effect. The analyses of comparisons of species, creeping and colonial bentgrass (tetraploidy) vs. velvet bentgrass (diploidy) and creeping vs. colonial bentgrass, were significant. The twoway interaction among these variables, the interaction between isolate and creeping and colonial vs. velvet were not significant for any parameter. However, the interaction between isolate and creeping vs. colonial cultivars, between isolate and cultivars (species) for second experiment was significant.

There were significant differences $(P=0.05)$ among the 17 commercial bentgrass cultivars for 8 isolates (Table 5). The millimeter of disease infection and colonization size based on measuring results by caliper were lower for cultivar Pennlinks (24.48 to $20.21 \mathrm{~mm}$ ) and cultivar Penneagle

Table 5. Susceptibility of seventeen bentgrass cultivars inoculated with eight isolates of $M$. nivale at $10^{\circ} \mathrm{C}$ in the dark after cold hardening at $5^{\circ} \mathrm{C}$ for 15 days

\begin{tabular}{llccc}
\hline \hline \multirow{2}{*}{$\begin{array}{l}\text { Bentgrass } \\
\text { species }\end{array}$} & Cultivars & \multicolumn{3}{c}{$\begin{array}{c}\text { Disease infection and colonization } \\
\text { (mm) }\end{array}$} \\
\cline { 3 - 5 } & & Expt. 1 & Expt. 2 & Mean \\
\hline Creeping & PST-9BNC & 34.11 & 26.73 & 30.42 \\
Creeping & L93 & 29.09 & 20.71 & 24.90 \\
Creeping & Penncross & 28.84 & 23.23 & 26.04 \\
Creeping & PennG2 & 27.39 & 23.44 & 25.42 \\
Creeping & Penneagle II & 27.03 & 18.44 & 22.74 \\
Creeping & Pennlinks II & 26.85 & 21.16 & 24.01 \\
Creeping & PennA4 & 26.84 & 20.11 & 23.48 \\
Creeping & Providence & 25.55 & 21.80 & 23.68 \\
Creeping & Pennlinks & 24.48 & 20.21 & 22.35 \\
Colonial & Bardot & 34.30 & 25.92 & 30.11 \\
Colonial & Glory & 32.40 & 27.82 & 30.11 \\
Colonial & Tiger & 31.80 & 26.38 & 29.09 \\
Colonial & Alister & 30.02 & 28.54 & 29.28 \\
Colonial & SR7100 & 31.24 & 28.34 & 29.79 \\
Velvet & Bavarica & 33.56 & 28.03 & 30.80 \\
Velvet & Vesper & 30.47 & 25.77 & 28.12 \\
Velvet & Greenwich & 31.45 & 27.32 & 29.38 \\
LSD(0.05) & & 6.18 & 4.18 & \\
\hline
\end{tabular}

Table 4. Analysis of variance of susceptibility of 17 bentgrass cultivars inoculated with eight isolates of $M$. nivale at $10^{\circ} \mathrm{C}$ in the dark after cold hardening at $5^{\circ} \mathrm{C}$ for 15 days

\begin{tabular}{|c|c|c|c|c|c|}
\hline \multirow{3}{*}{ Source } & \multirow{3}{*}{$\mathrm{df}$} & \multicolumn{4}{|c|}{ Disease infection and colonization (mm) } \\
\hline & & \multicolumn{2}{|c|}{ Expt. 1} & \multicolumn{2}{|c|}{ Expt. 2} \\
\hline & & F value & $P$ value & F value & $\mathrm{P}$ value \\
\hline Replicate & 3 & 1.05 & 0.3684 & 12.89 & $<.0001$ \\
\hline Creeping and Colonial vs. Velvet cultivars & 1 & 41.55 & $<.0001$ & 51.81 & $<.0001$ \\
\hline Creeping vs. Colonial cultivars & 1 & 172.69 & $<.0001$ & 193.75 & $<.0001$ \\
\hline Cultivar (species) & 14 & 6.60 & $<.0001$ & 17.64 & $<.0001$ \\
\hline Isolate & 7 & 36.57 & $<.0001$ & 336.63 & $<.0001$ \\
\hline Isolate $\times$ Creeping and Colonial vs. Velvet cultivars & 7 & 0.85 & 0.5431 & 2.02 & 0.0513 \\
\hline Isolate $\times$ Creeping vs. Colonial cultivars & 7 & 2.10 & 0.0426 & 5.02 & $<.0001$ \\
\hline Isolate $\times$ Cultivar (species) & 98 & 0.94 & 0.6433 & 1.31 & 0.0375 \\
\hline Error & 404 & & & & \\
\hline
\end{tabular}



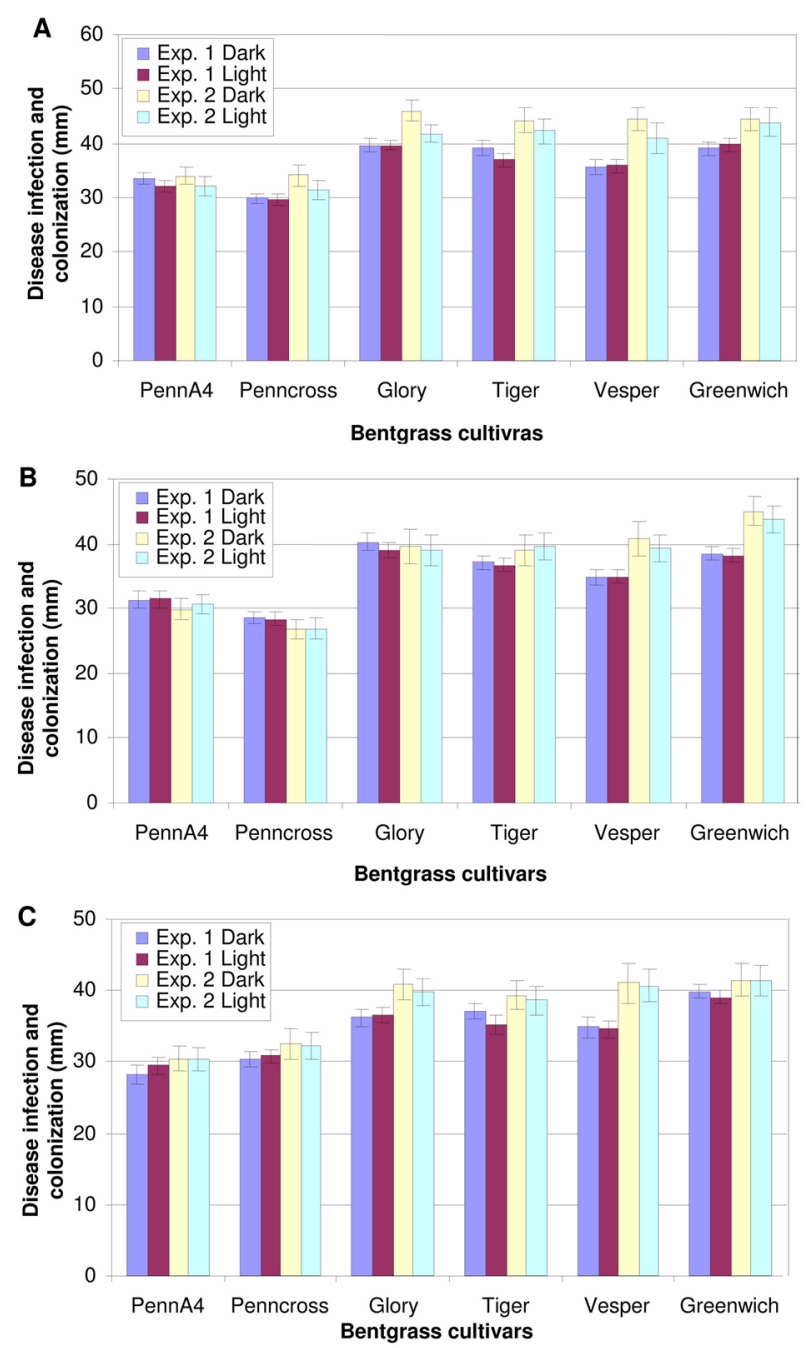

Fig. 2. Susceptibility of six bentgrass cultivars inoculated with three $M$. nivale isolates after cold hardening for 15,30 and 45 days at $5^{\circ} \mathrm{C}$. (A) 15 days of cold hardening, (B) 30 days of cold hardening, (C) 45 days of cold hardening.
$\Pi$ (27.03 to $18.44 \mathrm{~mm})$, creeping bentgrass species, than for cultivar SR7100 (34.11 mm to $26.73 \mathrm{~mm}$ ), cultivar Bardot (34.30 $\mathrm{mm}$ to $25.92 \mathrm{~mm}$ ) and cultivar Glory (30.40 $\mathrm{mm}$ to $27.82 \mathrm{~mm}$ ), colonial bentgrass species.

The pink snow mold isolates were also differed $(P=$ $0.05)$ in virulence based on results for disease infection and colonization. Among isolates of $M$. nivale were differed virulence. The millimeter of virulence of all the isolates in second experiment was lower than first experiment (Table $5)$.

Effect of days of cold hardening. The effect of days of cold hardening for 15 days, 30 days and 45 days on same 6 cultivars as above light effect experiments before inoculation with 3 isolates was significant (Fig. 2). Based on results in the two experiment, there were significant difference $(P=0.05)$ among days of cold hardening, 6 cultivars and 3 isolates of $M$. nivale. However, the light effect was not also significant difference such as above experiment of light effects (Table 6). The two-way interaction these variables were not significant for any parameter.

The reaction of host resistance based on both experiments, at 30 days of cold hardening were significantly higher than 15 days and 45 days. Creeping bentgrass cultivars also had lower disease infection and colonization than colonial bentgrass and velvet bentgrass cultivars.

Susceptibility of bentgrass cultivars in field. The susceptibility on bentgrass cultivars in growth chamber, was confirmed again in the field disease infection and colonization by inoculation to 2 years-old 12 commercial bentgrass cultivars. ANOVA showed significantly differences among cultivars within species, between creeping vs. colonial cultivars, and 3 isolates of $M$. nivale (Table 7). There were

Table 6. Analysis of variance of effects of six bentgrass cultivars inoculated with three M. nivale isolates after cold hardening for 15,30 and 45 days at $5^{\circ} \mathrm{C}$

\begin{tabular}{|c|c|c|c|c|c|}
\hline \multirow{3}{*}{ Source } & \multirow{3}{*}{ df } & \multicolumn{4}{|c|}{ Disease infection and colonization (mm) } \\
\hline & & \multicolumn{2}{|c|}{ Exp. 1} & \multicolumn{2}{|c|}{ Exp. 2} \\
\hline & & F value & P value & F value & P value \\
\hline Days of cold hardening & 2 & 3.1839 & 0.0425 & 3.7035 & 0.0255 \\
\hline Light and Dark & 1 & 3.3490 & 0.0680 & 1.1254 & 0.2894 \\
\hline Cultivars [species] & 3 & 9.9658 & $<.0001$ & 3.0375 & 0.0290 \\
\hline Isolates & 2 & 124.3095 & $<.0001$ & 330.5148 & $<.0001$ \\
\hline Replication & 3 & 5.9328 & 0.0006 & 0.0673 & 0.9772 \\
\hline Days of cold hardening $\times$ Cultivars [species] & 6 & 1.1035 & 0.3595 & 1.2594 & 0.2752 \\
\hline Light and Dark $\times$ Days of cold hardening & 2 & 0.4800 & 0.6191 & 0.1788 & 0.8363 \\
\hline Days of cold hardening $\times$ Isolates & 4 & 0.8130 & 0.5174 & 0.2360 & 0.9180 \\
\hline Light and Dark $\times$ Cultivars [species] & 3 & 0.2235 & 0.8801 & 0.0640 & 0.9788 \\
\hline Light and Dark $\times$ Isolates & 2 & 0.1737 & 0.8406 & 0.3054 & 0.7370 \\
\hline Cultivars [species] $\times$ Isolates & 2 & 1.3066 & 0.2530 & 0.7623 & 0.6000 \\
\hline Error & 397 & & & & \\
\hline
\end{tabular}


Table 7. Analysis of variance of susceptibility of twelve bentgrass cultivars inoculated with three isolates of $M$. nivale in the field

\begin{tabular}{lccccc}
\hline & & \multicolumn{3}{c}{ Disease infection and colonization (mm) } \\
\cline { 3 - 6 } Source & df & \multicolumn{3}{c}{ 10 Mar. } & \multicolumn{2}{c}{ 26 Mar. } \\
\cline { 3 - 6 } & & F value & P value & F value & P value \\
\hline Replicate & 3 & 11.33 & $<.0001$ & 12.24 & $<.0001$ \\
Creeping vs. Colonial cultivars & 1 & 69.74 & $<.0001$ & 64.74 & $<.0001$ \\
Cultivar (species) & 9 & 2.17 & 0.0314 & 2.20 & 0.0291 \\
Isolate & 2 & 229.81 & $<.0001$ & 249.84 & $<.0001$ \\
Isolate $\times$ Creeping vs. Colonial cultivars & 2 & 2.32 & 0.1046 & 2.17 & 0.1201 \\
Isolate $\times$ Cultivar (species) & 18 & 1.59 & 0.0802 & 1.25 & 0.2430 \\
Error & 90 & & & & \\
\hline
\end{tabular}

${ }^{a}$ The day of disease rating

Table 8. Susceptibility of 12 bentgrass cultivars inoculated with three isolates of M. nivale at O. J. Noer Research Facility, Verona, WI

\begin{tabular}{llccc}
\hline \hline \multirow{2}{*}{$\begin{array}{l}\text { Bentgrass } \\
\text { Species }\end{array}$} & Cultivars & \multicolumn{3}{c}{$\begin{array}{c}\text { Disease infection and colonization } \\
\text { (mm) }\end{array}$} \\
\cline { 3 - 5 } & & 10 Mar. & 26 Mar. & Difference \\
\hline Creeping & PST-9BNC & 56.46 & 68.48 & 12.02 \\
& PennA4 & 44.33 & 51.50 & 7.17 \\
& PennG2 & 48.99 & 57.45 & 8.45 \\
& Pennlinks & 40.66 & 51.91 & 8.07 \\
& Pennlinks II & 41.60 & 49.18 & 7.58 \\
& Penncross & 39.68 & 50.67 & 10.99 \\
Colonial & Penneagle II & 40.54 & 48.61 & 9.45 \\
& Glory & 58.46 & 71.73 & 13.27 \\
& Alister & 54.93 & 61.75 & 6.82 \\
& Bardot & 54.44 & 63.64 & 9.20 \\
Velvet & SR7100 & 50.44 & 57.78 & 7.34 \\
LSD (0.05) & Greenwich & 44.79 & 57.07 & 12.27 \\
\hline
\end{tabular}

The day of disease rating.

Symptom size $(\mathrm{mm})$ was measured as patch diameter in plots after snow melt

no significant interaction between cultivars and isolates. Of 12 commercial cultivars, 6 creeping bentgrass cultivars were showed less susceptible than 5 colonial and a velvet cultivar to pink snow isolates during rated of two time (Table 8). Disease development increased after measuring the symptoms from Mar. 10 to Mar. 26, 2004 and was showed difference among cultivars.

\section{Discussion}

The growth chamber method developed in this study showed consistent disease development by $M$. nivale isolates throughout all experiments in the growth chamber. We have therefore developed a modified methods from Gaudet
(1991) and Nagasima and Abe (1996) for the inoculation and incubation to evaluate bentgrass cultivar susceptibility to pink snow mold. According to this newly modified method (Chang et al., 2006a, 2006b), pink snow mold symptoms caused by $M$. nivale were successfully reproduced by direct inoculation onto plants using a mycelium suspension. A high level of disease infection and colonization was obtained by incubating inoculated plants at $10^{\circ} \mathrm{C}$ with saturated moisture on the plants using plastic container containing saturated culture media for 10 days after inoculation. Disease development was observed by three days after inoculation with peak symptom expression occurring at 10 days in susceptible cultivars. We found that saturated moisture on the plants was very important for consistent disease development, but disease expression was possible between $5^{\circ} \mathrm{C}$ to $15^{\circ} \mathrm{C}$. The optimum temperature was $10^{\circ} \mathrm{C}$ for incubation (date not shown).

Previous studies reported that $M$. nivale requires a high humidity and low temperature to develop disease infection and colonization during incubation after inoculation onto winter wheat (Dahl, 1934; Holmes and Channon, 1975), but Nagasima and Abe (1996) reported that low temperature were not required for the disease infection and colonization. Our data support the finding of Dahl (1934) and Holmes and Channon (1975) in that decreased chamber moisture results in poor disease infection and spread. In the 5 to $10^{\circ} \mathrm{C}$ chamber there was also an abundant growth of mycelia and a rapid spread of the fungus over the leaves, which symptoms were detected in the finding of Dahl (1934) and Holmes and Channon (1975). Miedaner et al. (1993) also emphasized the importance of temperature, and Cassini (1981) suggested that variable results obtained by temperature effect by artificial or natural inoculation.

When different concentrations of inoculums were applied to the three bentgrass species (creeping bentgrass cultivar "Penncross", colonial bentgrass cultivars "Tiger" and velvet bentgrass cultivars "greenwich"), disease infection and development caused by three M. nivale isolates, were 
directly correlated to the increasing amount of inoculum. Differences in disease infection and colonization for the three species were significantly different for the treatments of $0.1 \mathrm{~g}$ and $0.2 \mathrm{~g}$ fresh mycelia weight per $\mathrm{mL}$ in the SW47 isolate, but other isolates evenly infected and colonized the bentgrasses at these amounts of mycelium. Therefore, we used $0.2 \mathrm{~g}$ fresh mycelia weight per $\mathrm{ml}$ for evaluation of 17 bentgrass cultivars. In case of cultivar Greenwich, the difference for the degrees of disease infection and colonization was shown by the infection of the isolates as compared to cultivars Tiger and Penncross (date not shown).

Seventeen cultivars of 3 bentgrass species were evaluated as susceptibility in inoculation. Creeping bentgrass species were less susceptible than velvet and colonial bentgrass species (Table 5). Previous studies showed similar susceptibility patterns among bentgrass species. Creeping species were rated as resistance to pink snow mold in the field, whereas colonial and velvet species were rated susceptable (Dahl, 1934; Gaudet, 1994; Smith, 1980, 1978; Tyson, 1936). No evidence of a less susceptibility response in genotypic background was observed on creeping bentgrass cultivars to pink snow mold. Creeping bentgrass has an allotetraploid genotype with $\mathrm{A}_{2} \mathrm{~A}_{2} \mathrm{~A}_{3} \mathrm{~A}_{3}$ genome whereas colonial is also allotetraploid but they have $A_{1} A_{1} A_{2} A_{2}$ genomes (Jones, 1956). Thus colonial is more related to other species (dayland bentgrass) than to creeping bentgrass within tetraploidy. The velvet cultivars have a diploid $A_{1} A_{1}$ genome, and are significantly different from creeping cultivars. By comparing the creeping to colonial or velvet cultivars, one may speculate that the $\mathrm{A}_{3} \mathrm{~A}_{3}$ genome is actually conferring the resistance to creeping species. Further experiments are needed to validate this hypothesis. Genotypic resistance is known to interact with plant age and cold hardening in the expression of snow mold resistance (Bruehl, 1982; Gaudet and Kozub, 1991). A limited amount of genotypic variation occurs among winter wheat cultivars in their resistance to snow mold (Gaudet and Kozub, 1991). Furthermore, a positive association between genotypic cold hardening and resistance to Microdochium borealis has been reported among cultivars of winter wheat and grasses (Arsvoll and Larsen, 1977; Amano, 1987). Several resistance components may contribute to the resistance in creeping bentgrass cultivars (Hömmö, 1994), and resistance is further influenced by plant size, storage, and utilization of carbohydrates by the plant (Bruehl, 1982; Gaudet, 1994).

Virulence varied significantly among $M$. nivale isolates in both experiments (Table 5). We noted an interesting isolate effect in that the isolates caused different amount of disease in the cultivars. Isolates NE33 and NE39 caused less disease infection and colonization in all the cultivars compared to isolates SE 25, SW47 and SW1. This is very important information for turfgrass breeders since it suggests that cultivars breed for resistance against one or a few isolates can hold up their resistance may have risks. In field condition for a longer period of time where due to genetic shift in the pathogen population, the host resistance tends to break down faster.

A significant difference was detected in the interaction between isolates versus creeping and colonial cultivars $(P=$ 0.042 and $P=<.0001$ ) for both experiments (Table 4$)$. The interaction was not the result of a differential response by 17 bentgrass cultivars and was not consistent among two independent experiments. In experiment 1, isolates NE25 and SW47, induced moderate disease infection and colonization on 15 cultivars, but had the highest on Bardot cultivars and PST-9BNC cultivars. These effects may have contributed to this interaction. In experiment 2, isolates NW70 and NE33, had the highest disease infection and colonization on Alister cultivars and Glory cultivars, and may have contributed to this interaction.

Susceptibility of bentgrass cultivars to $M$. nivale may be influenced by light. Therefore, we investigated effects of with light and no light for cold hardening before inoculation with $M$. nivale isolates. During the cold hardening, dark treatments, were performed in dark simulate snow cover conditions for 15 day. We found that effects of light and no light on disease infection and colonization were not significantly difference for both experiments (date not shown). During cold hardening with light and no light condition for 15 days before inoculation with isolates, the effects of light, were not significant difference on disease infection and colonization to 3 bentgrass species ( 2 creeping cultivars, 2 colonial cultivars and 2 velvet cultivars). There were also significant difference among 6 bentgrass cultivars with species and 3 isolates of $M$. nivale. The two-way interaction between light and isolates, between light and cultivars were not significant for any parameter. Therefore, light treatment during the cold hardening for 14 days did not affect mean disease infection and colonization by $M$. nivale isolates to bentgrass species. However, Nagasima and Abe (1996), reported light effect on the disease infection in winter wheat. The plants subjected to the dark remained susceptible but developed winter wheat resistance to the disease caused by $M$. nivale rapidly when exposed to low light intensities of $150 \mu \mathrm{mol} \cdot \mathrm{m}^{-2} \cdot \mathrm{s}^{-1}$ at $2^{\circ} \mathrm{C}$.

Host resistance to $M$. nivale isolates was influenced by cold hardening at low temperature before inoculation in growth chamber in both experiments (Fig. 2). Increased days of cold hardening did not increase host resistance (Table 6), but had trends of increasing host resistance reaction among bentgrass species to $M$. nivale isolates by 30 days of cold hardening (Gaudet and Bhalla, 1988; Arsvoll, 1977; Tronsmo, 1985). We also found that plants resistance changed significantly in unhardened and hard- 
ened plants. Unhardened plants were showed much more susceptibility to pink snow mold when compared to hardened plants for 15 day, 30 days and 45 days. Partially hardened or unhardened cereals and grasses were less resistant to snow mold than completely hardened plants (Arsvoll, 1977; Tronsmo, 1985). Low temperature hardening also induced resistance to other fungal diseases such as rust (Tronsmo, 1984) and powdery mildew (White and Jenkyn, 1995) suggesting that disease resistance might be nonspecifically developed during low temperature hardening. Several changes occurring in plants during hardening could be responsible for the increase in snow mold (M. nivale) resistance in winter wheat (Ergon et al., 1998).

Susceptibility of two-year old 12 bentgrass cultivars to $M$. nivale in field was also varied among cultivars such as in growth chamber experiments. Uninoculated plots with $M$. nivale isolates showed no disease symptom. Inoculated plots showed consistent development of pink snow mold patches same to natural symptom in spring after snow melts. We demonstrated that growth chamber and field measurements results with inoculated of isolates were showed high correlation to evaluate susceptibility of bentgrass. Field results closely correspond to growth chamber results where creeping bentgrass cultivars appears to be less susceptible than colonial and velvet species. However, the Greenwich cultivar of velvet bentgrass species was less susceptible than the PennG2 cultivar of creeping bentgrass species to three $M$. nivale isolates when compared to growth chamber experiments inoculated with 8 isolates. This response may be influenced by environment conditions or resistant components (Bruehl, 1982; Gaudit, 1994) in the field. In grasses and cereals, different species and varieties in resistance to M. nivale show variation (Pulli et al., 1996). A correlation between resistant to $M$. nivale and different species of the snow mold fungi Typhula has been found in grasses and cereals (Iriki et al., 2002). Although correlation between resistances to different winter stress factors has been found in grasses (Nagasima and Abe, 1997), since ranking of genotypes according to their resistance is not consistent when studying different winter stress factors (Proncuzuk and Zagdanska, 1993).

Comparison of the susceptibility test for commercial bentgrass cultivars to $M$. nivale in growth chamber experiments and in fields demonstrates that the growth chamber method is a useful technique to evaluate commercial bentgrass cultivars for susceptibility and resistance to $M$. nivale isolates. The fresh mycelium suspension inoculation and incubation methods allow evaluation of susceptibility of bentgrass cultivars to pink snow mold isolates in growth chamber. Successful application of this technique would help breeders for evaluating resistance of cultivars to the isolates of $M$. nivale. The growth chamber method used in this study could shorten the time for screening of many bentgrass cultivars to pink snow mold, and provide a good prospective evaluation to predict disease responses of bentgrass cultivars in the field. Therefore, susceptibility screening of bentgrass to pink snow mold in the growth chamber would increase the power to test host resistance, therefore, can increase the number of cultivars or breed lines that can be tested. All these results can provide useful information about bentgrass cultivars susceptibility to $M$. nivale isolates affected by the light and cold hardening treatment.

\section{References}

Amano, Y. 1987. Winter wheat breeding for resistance to snow mold and cold hardiness: Estimation of genetic effects for resistance to snow mold and freezing by the use of half diallel cross analysis. Bull. Hokkaido Pref. Agric. Exp. Sta. 56:31-38.

Arsvoll, K. 1977. Effect of hardening, plant age, and development in Phleum pretense and Festuca pratensis on resistance to snow mold fungi. Meld. Sci. Rep. Agri. Univ. Norway. 56:113.

Arsvoll, K. and Larsen, A. 1977. Effect of nitrogen, phosphorus, and potassium on resistance to snow mold fungi and on freezing tolerance in Phleum pretense. Meld. Norg. LandbrHøgsk. 56:1-14.

Bruehl, G. W. 1982. Developing wheat resistance to snow mold in Washington State. Plant Dis. 66:1090-1095.

Cassini, R. 1981. Fusarium disease of cereals in Western Europe. In: Nelson, P. E., Toussoun, T. A. and Cook, R. J. Fusarium disease, Biology, and taxanomy. Pennsylvania State Univ. Press, USA. pp. 56-63.

Chang, S. W., Chang, T. H., Tredway, L. and Jung, G. 2006 a. Aggressiveness of Typhula ishikariensis to cultivars of bentgrass species (Agrostis spp.) under controlled environment conditions. Plant Dis. 90:951-956.

Chang, S. W., Scheef, E., Abler, R. A. B., Clayton, M. K., Thomson, P., Johnson, P. and Jung, G. 2006b. Distribution of Typhula species and T. ishikariensis varieties in Wisconsin, Utah, Michigan and Minnesota states. Phytopathology 96: 926-933.

Couch, H. B. 1973. Disease of Turfgrass. New York. p. 348.

Dahl, A. S. 1934. Snow mold of turfgrasses as caused by Fusarium niavle. Phytopathology 24:197-214.

Ergon, A., Klemsdal, S. S. and Tronsmo, A. M. 1998. Interaction between cold hardening and M. nivale infection on expression of pathogenesis related genes in winter wheat. Physiological and Molecular Plant Pathology 53:301-310.

Gaudet, D. A. and Bhalla, M. K. 1988. Survey for snow mold disease of winter cereals in central and north Alberta, 1983-87. Can. Plant Dis. Surv. 68:15-20.

Gaudet, D. A. and Kozub, G. M. 1991. Screening winter wheat for resistance to cottony snow mold under controlled conditions. Can. J. Plant Sci. 71:957-965.

Gaudet, D. A. 1994. Progress toward understanding interaction between cold hardening and snow mold resistance and devel- 
opment of resistance cultivars. Can. J. Plant Pathol. 16:241246.

Hitchcock, A. S. 1951. Manual of the grasses of the United States. USDA Misc. Publ. 200. U.S. Gov. Washington, DC. 260 p.

Holmes, S. J. I. and Channon, A. G. 1975. Glasshouse studies on the effect of low temperature on infection of perennial ryegrass seedings by Fussarium nivale. Ann. Appl. Biol. 79:43-48.

Hömmö, L. M. 1994. Screening winter rye cultivars for snow mold (Microdochium nivale) resistance. Plant Pathol. 43:740-750.

Iriki, N., Nakajima, T. and Kawakami, A. 2002. Reaction of winter wheat cultivars to artificially inoculated seed-borne pink snow mold. Breed Sci. 52:231-233.

Jones, K. 1956. Species differentiation in Agrostis II. Cytological relationships in Agrostis canina L. J. Genet. 54:370-376.

Latch, G. C. M. 1973. Disease of turfgrass and disease control. pp. 167-176.

Madison, J. H., Peterson, L. J. and Hodges, T. K. 1960. Pink snow mold on bentgrass as affected by irrigation and fertilizer. Agron. J. 52:591-592.

Miedaner, T., Hoxter, H. and Geiger, H. H. 1993. Development of a resistance test for winter rye to snow mold (Microdochium nivale) under controlled environment conditions in regard to field inoculations. Can. J. Bot. 71:136-144.

Nagasima, T. and Abe, J. 1996. Enviromental factors affecting expression of resistance to pink snow mold caused by Microdochium nivale in winter wheat. Can. J. Bio. 74:1783-1788.

Pulli, S., Hjortesholm, K., Larsen, A., Gudleifsson, B., Larsson,
S., Kristiansson, B., Hömmö, L. M., Trensmo, A. M., Ruuth, P. and Kristiansson, K. 1996. Development and evaluation of laboratory testing methods for winter hardiness breeding. Publications Nordic gene bank. 32:1-68.

Prónclzuk, M. and Zagdánska, B. 1993. Effect of Microdochium nivale and low temperature on winter survival of perennial ryegrass. J. Phytopathol. 138:1-8.

Smith, J. D. 1957. The control of fusarium patch disease with fungicides. In the control of certain diseases of sports turfgrasses in the British Isles. M. Sc. Thesis, Univ. Durham. pp. 1-96.

Smith, J. D. 1978. Snow molds of grasses and winter cereals. Can. Agric. 24:8-11.

Smith, J. D., Jackson, N. and Woolhouse, A. R. 1989. Fungal Diseases of Amenity Turfgrass. London. E\&F.N. Spon Ltd. 450 p.

Smiley, R. W., Dernoeden, P. H. and Clarke, B. B. 1992. Compendium of Turgrass Diseases. Minnesota: The American phytopathological Society. pp. 28-32.

Tronsmo, A. M. 1984. Resistance to the rust fungus Puccinia poae-nemoralis in Poa pratensis induced by low temperature hardening. Can. J. Bot. 66:2891-2892.

Tronsmo, A. M. 1985. Predisposing effects of low temperature on resistance to winter stress factors in grasses. Acta Agric Scand. 34:210-220.

Tyson, J. 1936. Snow mold injury to bentgrasses. Quart. Bull. Mich. Agr. Expt. Sta. 19:87-92.

White, N. and Jenkyn, J. F. 1995. Effects of sowing date and vernalisation on the growth of winter barley and its resistance to powdery mildew (Erysiphe graminis f. sp. hordi). Ann. Appl. Bio. 126:269-283. 